\title{
ESTUDO CRIMINOLÓGICO DO ATO INFRACIONAL NO DISTRITO DE ICOARACI- BELÉM- PA
}

\section{STUDY OF CRIMINOLOGY JUVENILE JUSTICE IN ICOARACI DISTRICT - BELÉM- PA}

\author{
${ }^{1}$ Joao Paulo Carneiro Goncalves Ledo
}

\section{RESUMO}

Pesquisa de campo sobre o programa penal juvenil posto em prática no Distrito de Icoaraci, que pertence ao município de Belém, capital do Estado do Pará. Tem como inspiração a pesquisa de Vera Malaguti Batista (2013). Faz uma abordagem histórica. Reflete que na prática a doutrina da proteção integral pode ter caráter de reversibilidade, pois mecanismos aparentemente voltados à satisfação dos direitos humanos, em sua ação concreta, podem deflagrar violação dos próprios direitos humanos. Apresenta os dados coletados e finaliza com uma abordagem crítica sobre seletividade e violação de direitos.

Palavras-chave: Seletividade, Delinquência juvenil, Pesquisa

\begin{abstract}
Field Research about juvenile criminal program put into practice in Icoaraci District, belongs the city of Belém, Pará State. As inspiration has one Vera Malaguti Batista research (2013 ). Making a historical approach. Reflects in practice the doctrine of integral protection can have character of reversibility because mechanisms apparently aimed at the satisfaction of human rights in your concrete action, trigger can own violation of human rights. Shows the data collected and ends with a critical approach about selectivity and violation of rights.
\end{abstract}

Keywords: Selectivity, Juvenile delinquency, Scientific research

\footnotetext{
${ }^{1}$ Graduado em Direito pela Universidade da Amazônia - UNAMA, Belem - PA (Brasil).

E-mail: jp_carneiro@ hotmail.com
} 


\section{INTRODUÇÃO}

A pouco menos de 20 vinte anos atrás Vera Malaguti Batista concluía sua dissertação de mestrado com uma pesquisa de campo sobe os processos de criminalização acentuadamente seletivo da juventude Carioca, pesquisa realizada com processos do $2^{\mathrm{a}}$ Juizado de Menores do Rio de Janeiro, existentes no Arquivo Nacional. A dissertação foi aprovada e publicada em fo rma de livro, a primeira edição da obra "Difíceis ganhos fáceis: Drogas e Juventude Pobre no Rio de Janeiro"1, publicada pela editora Revan em 01 de janeiro de 1998.

A denúncia de que seria a justiça juvenil, desde a sua fundação, a parte mais sensível em todo o sistema punitivo, a mais problemática, onde o "caráter seletivo e distributivo alcançam seu ponto mais alto" (2013, p.25), serviu de base para inquietação e de fonte de inspiração para outros pesquisadores.

Visando analisar a seletividade a partir do programa penal juvenil posto em prática no Distrito de Icoaraci, que pertence ao município de Belém, capital do Estado do Pará, foi realizado pesquisa de campo, através de análise dos processos judiciais, em especial da ata da audiência de apresentação prevista no $\S 1^{\circ}$, do artigo 184 do Estatuto da Criança e do Adolescente, Lei no 8069/90, nos meses de março, abril e maio de 2015, tendo sido feitos 105 (cento e cinco) entrevistas e análises processuais, o que representa aproximadamente 17\% (dezessete por cento) dos processos em trâmite envolvendo ato infracional na Vara de Infância.

$\mathrm{Na}$ análise do material coletado importantes são, além dos aportes teóricos Vera Malaguti Batista (2013), as lições da Criminologia Crítica, que em oposição à Criminologia positivista desloca o objeto de estudo da ciência. Enquanto a Criminologia Positiva (paradigma etiológico) pretende desvendar as causas da criminalidade, encarada como dado antológico, pré-constituído - ou seja, seu objeto é criminalidade -, a Criminologia Crítica (paradigma da reação social), por seu turno, mostra o crime como qualidade atribuída ao comportamento ou pessoas pelo sistema de justiça criminal - seu objeto. é, portanto, não a criminalidade, mas a criminalização: a criminalidade é um fato socialmente constituído pela distribuição de cargas negativas a fatos e a pessoas, por meio de processos de criminalização.

\footnotetext{
${ }^{1}$ Nos trabalharemos com a segunda edição que foi publicada em 2003 e reimpressa em 2013.
} 
Baratta (2012, p. 160) aponta que duas são as consequências; a primeira seria o deslocamento do enfoque teórico do autor para as condições objetivas, estruturais e funcionais, que estão na origem do fenômeno do desvio. A segunda seria o deslocamento do interesse cognoscitivo das causas do desvio criminal para os mecanismos sociais e institucionais, por meio dos quais é construída a "realidade social" do desvio, ou seja, para os mecanismos por meio dos quais são criadas e aplicadas as definições de desvio e criminalidade e realizados os processos de criminalização.

$\mathrm{Na}$ perspectiva da Criminologia Crítica, ainda segundo Baratta (2012, p. 161), a criminalidade se revela, principalmente, como um status atribuído a determinados indivíduos, mediante uma dupla seleção: em primeiro lugar, a seleção de bens protegidos penalmente, e dos comportamentos ofensivos destes bens, descritos nos tipos penais; em segundo lugar, a seleção dos indivíduos estigmatizados entre todos os indivíduos que realizam infrações a normas penalmente sancionadas.

A pesquisa da Vera Malaguti Batista (2013, p.35) apontou que as drogas seriam o principal fator de criminalização da juventude, pois $49 \%$ dos adolescentes entraram no sistema de apuração no ato infracional envolvidos com a acusação de tráfico (38\%) e consumo (11\%) de drogas. A maioria desses meninos vêm de morros, favelas e bairros pobres e $38 \%$ são analfabetos.

Passados esses 20 (vinte) anos e em locais geográfico e historicamente diferentes os dados são parecidos e a seletividade parece ter sido mais acentuada ainda, conforme se verá adiante.

Por outro lado, o momento é demasiadamente oportuno para se debater os processos de criminalização da juventude, em especial, ante ao fato de que se discute no Congresso Nacional a redução da maioridade penal para crimes hediondos ${ }^{2}$ e a reforma das medidas socioeducativas, a pesquisa de campo e a visão crítica que nos brinda a criminologia crítica permite chegar conclusões importantes sobre a seletividade na apuração de ato infracional, bem como auxilia os operadores do direito a formarem uma visão crítica sobre a delinquência juvenil na referida localidade.

\footnotetext{
2 O Plenário da Câmara dos Deputados aprovou em primeiro turno, em 02/07/2015, a redução da maioridade penal, de 18 para 16 anos, nos casos de crimes hediondos (estupro, sequestro, latrocínio, homicídio qualificado e outros), homicídio doloso e lesão corporal seguida de morte. O texto aprovado é uma emenda dos deputados Rogério Rosso (PSD-DF) e Andre Moura (PSC-SE) à proposta de emenda à Constituição da maioridade penal (PEC 171/93). Foram 323 votos a favor e 155 contra, em votação em primeiro turno. Os deputados precisam ainda analisar a matéria em segundo turno. (CAMARA DOS DEPUTADOS, 2015, não paginado).
} 


\section{A SELETIVIDADE ESTRUTURAL}

O sistema penal é o conjunto das agências que operam a criminalização (primária e secundária) ou que convergem na produção da mesma. A criminalização primária seria a decisão política de sancionar determinada conduta como ilícita com uma pena (elaboração de tipos penais pelo Poder Legislativo). A criminalização secundária, por seu turno, seria a ação punitiva sobre as pessoas que infringem as normas penais, ou seja, o programa penal posto em prática (ZAFFARONI; BATISTA, ET AL, 2003, p. 47)

A seletividade operacional da criminalização secundária atinge apenas aqueles que têm baixa defesas perante o poder punitivo, aqueles que se tornam mais vulneráveis à criminalização secundária porque: a) suas características pessoais se enquadram no estereótipo criminal; b) sua educação só lhes permite realizar ações ilícitas toscas e, por conseguinte, de fácil detecção; e c) porque a etiqueta suscita a assunção do papel correspondente ao estereótipo, com o qual o seu comportamento acaba correspondendo ao mesmo. Em suma, as agências acabam selecionando aqueles que circulam pelos espaços públicos com o figurino social dos delinquentes, prestando-se à criminalização - mediante as suas obras toscas - como seu inesgotável combustível.

O estereótipo criminal se compõe de caracteres que correspondem a pessoas em posição social desvantajosa e, por conseguinte, com educação primitiva, cujos eventuais delitos, em geral, apenas podem ser obras toscas, o que só faz reforçar ainda mais os preconceitos racistas e de classe, à medida que a comunicação oculta o resto dos ilícitos cometidos por outras pessoas, cometidos de uma maneira menos grosseira. Isto leva a conclusão pública de que a delinquência se restringe aos segmentos subalternos da sociedade, e este pensamento acaba sendo assumido por equivocados pensamentos humanistas que afirma serem a pobreza, a educação deficiente etc. as causas do delito, fatores condicionantes dos ilícitos desses segmentos sociais, mas, sobretudo, de sua criminalização, ao lado qual se espalha, impune, todo o oceano de ilícitos dos outros segmentos, que os comete com menor rudeza ou mesmo com refinamento.

O sistema opera, pois, em forma de filtro para acabar selecionando tais pessoas. Cada uma delas se acha em um certo estado de vulnerabilidade ao poder punitivo que depende de sua correspondência com um estereótipo criminal: o estado de vulnerabilidade será mais alto ou mais baixo consoante à correspondência se o estereótipo for maior ou menor. A pessoa que se enquadra no estereótipo não precisa fazer grande esforço para colocar-se em risco 
criminalizante (e, ao contrário, deve esforçar-se muito para evitá-lo), porquanto se encontra num estado de vulnerabilidade sempre significativo.

Quem, ao contrário, não se enquadrar em um estereótipo, deverá fazer um esforço considerável para posicionar-se em situação de risco criminalizante, uma vez que provém de um estado de vulnerabilidade relativamente baixo. Os raríssimos casos em que o que não se enquadra no estereótipo é criminalizado serve para alimentar a ilusão da irrestrita criminalização, que não leva em consideração a classe social, o que na verdade serve unicamente para encobrir a seletividade do sistema.

Por tais razões, Zaffaroni; Batista, et al. (2003, p. 47) afirmam que a seletividade é estrutural e, por conseguinte, não há sistema penal no mundo cuja regra geral não seja a criminalização secundária em razão da vulnerabilidade do candidato, sem prejuízo de que, em alguns, esta característica estrutural atinja graus e modalidades aberrantes.

Assim, a criminalização corresponde apenas supletivamente à gravidade do delito (conteúdo injusto do fato): esta só é determinante quando, por configurar um fato grotesco, eleva a vulnerabilidade do candidato. Em síntese: a imensa disparidade entre o programa de criminalização primária e suas possibilidades de realização como criminalização secundária obriga a segunda a uma seleção que, em regra, recai sobre fracassadas reiterações de empreendimento ilícitos que insistem em seus fracassos, por meio do papel que o próprio poder punitivo lhes atribui ao reforçar sua associação com as características de certas pessoas mediante o estereótipo seletivo.

\section{O HISTÓRICO DA SELETIVIDADE NA APURAÇÃO DE ATO INFRACIONAL NO BRASIL}

Luiz Tardei de Aragão (1991, apud BATISTA, 2013, p.65) aborda a eficácia simbólica da violência como troca nas relações sociais brasileiras. Ele descreve a violência social presente nas relações com a mãe preta, a ama de leite e a babá. Estas relações estariam presentes nos fundamentos do processo de socialização das elites brasileiras. Ao complexo do mediterrâneo da mãe como pureza, renúncia e doação se somaria a violência contra a mulher escrava e a questão cultural decorrente do sentido da propriedade na sociedade brasileira. A figura da mãe no Brasil se decomporia em duas: a de uma mãe biológica, a cujo corpo não se tem acesso, mas que é socialmente reconhecida, e de uma mãe preta à qual se tem acesso, mas que não é socialmente reconhecida. 
Se as amas-de-leite, as mães pretas, e as babás oferecem seus corpos e seu leite para os filhos da elite, o que teria acontecido com os filhos das amas-de-leite? Eles foram sempre um estorvo, no mundo escravo e no mundo pós-emancipação, povoando as rodas expostos, vagando pelas cidades, realizando pequenos biscates.

Vara Malaguti Batista (2013, p.39), ao estudar os processos arquivados da "Vara de Órfãos" no período de 1907 a 1914 aponta que a maioria de processos eram de meninas, servindo a referida vara como uma "agência de serviços domésticos", que saiam do "Azylo de Menores" para trabalhar "à soldada" em casas de família. A "soldada” era uma prática comum em que uma família tomava sob sua responsabilidade jovens com idade entre 12 e 18 anos, comprometendo-se a "vesti-la, calçá-la, alimentá-la e depositar mensalmente em caderneta de poupança na Caixa Econômica Federal”.

A pesquisa apontou os sentimentos de posse, herança da escravidão, perpetuados nesses procedimentos transparecem na análise, pois a vida nos asilos, os trabalhos forçados nas "soldadas", as fugas e consequentes detenções pela polícia fazem pensar em "vidasprisões", pois não havia escapatória possível ao destino de quem entrava nesse sistema de "asilo, polícia, juizado e soldadas".

É instituído em 1923 a Justiça de Menores, sendo criado o primeiro Juizado de Menores e depois o Código de Menores, tendo como figura central o Juiz Mello Mattos. Trata-se de um sistema influenciado pelas ideias de Lombroso. É neste momento em que a palavra menor passa a se associar definitivamente a crianças pobres, a serem tuteladas pelo Estado para a preservação da ordem e asseguramento da modernização capitalista em curso.

A pesquisadora $(2003$, p.71) aponta que no referido período é "impressionante como a maioria esmagadora dos casos se refere a meninos pobres; as elites resolvem seus casos em outras instâncias, informais e não segregadoras”.

A partir dos anos trinta, o cenário muda. O período de 1930 a 1945 seria a fase da tentativa de implantação do Estado Social Brasileiro, período em que o Estado Novo tentou fazer das políticas sociais o instrumento de incorporação de massas urbanas ao projeto nacional, liderado por Getúlio Vargas.

Neste período foi criando uma infra-estrutura de atendimento às crianças que teve no SAM (Serviço de Assistência ao Menor) seu principal alicerce. Sob orientação correcional repressiva, o sistema baseava-se em reformatórios, casas de correção, em patronatos agrícolas e escolas de aprendizagem de ofícios urbanos. 
O golpe militar de 1964 produz novo pacto politico-social em que o Estado brasileiro aprofunda seu caráter autoritário de acordo com a doutrina de segurança nacional. Esta doutrina, amplamente utilizada pela tecnocracia do governo militar se legitima através da luta contra os "inimigos internos" e a ameaça comunista. A segurança interna faz com que o Estado esteja preparado para “de maneira eficaz, anular as pressões e os antagonismos dentro do cenário político".

Estas mudanças produzem um novo corte no sistema. É a lei 4513/64 que cria a Política Nacional de Bem-Estar do Menor e a Lei 6697/79 que cria no novo Código de Menores dirigidos aos menores em situação irregular. É criada a Funabem e as Febem, órgão executórios estaduais.

Para a Maria de Fátima Migliari (1993, apud Batista, 2013, p.78) a criação da Funabem está relacionada a Doutrina da Segurança Nacional, aonde a questão da juventude pobre se encaixa na doutrina de defesa do Estado. A Funabem passou a atuar como a propagadora de ideologia em nível nacional, com discurso ideológico fortalecedor das representações negativas da juventude pobre, prenhe dos discursos darwinistas sociais e dos determinismos da virada do século. A Funabem faz o marketing das políticas sociais da ditadura, no contexto dos "fatores psicossociais" da política de Segurança Nacional. O novo código "menorista" trata da situação irregular como estado de "patologia social ampla". Para Migliari, a situação irregular é metáfora da criança/adolescente pobre que precisa estar sobre controle rígido de um conjunto de normas rígidas. O jovem em "situação irregular" é processado e entra no circuito penal sem a presença de um advogado. Um dos eixos do processo menorista é o não reconhecimento do menor como pessoa, mas como alguém a ser tutelado, como bem pondera Zaffaroni (1992, 640):

\footnotetext{
“Ao longo de toda a história da Humanidade, a ideologia tutelar em qualquer âmbito resultou em sistema processual inquisitório. O 'tutelado' sempre o tem sido em razão de alguma inferioridade (teológica, racial, cultural, biológica, etc)"
}

Aquele que precisava ser "cuidado" pelo Estado, a fim de cura de suas patologias, não precisa de um "advogado-defensor", eis que não responde ao processo visando a sua "punição", mas a sua "reintegração a sociedade e a cura de suas patologias físicas e sociais".

Atualmente vigora a "doutrina da proteção integral", que é mencionada na Constituição Federal de 1988 e se inicia a partir da vigência do ECA (Lei nº 8.069, de 13 de Julho de 1990), como aplicação de tese vencedora. A doutrina da proteção integral (ARAUJO, 
2008, p.20) se baseia em dois pilares: o reconhecimento do adolescente como pessoa em desenvolvimento e do princípio do melhor interesse. Institui-se regras processuais, fruto na verdade da Doutrina da ONU da Proteção Integral à Criança e ao adolescente.

Segundo a doutrina Ishida (2014, p.246), o Estatuto da Criança e do Adolescente perfilha a "doutrina da proteção integral", baseada no reconhecimento de direitos especiais e específicos de todas as crianças e adolescentes. Teve sua matriz ideológica baseado no texto constitucional de 1988, art.227, que institui a chamada prioridade absoluta, que constitui uma nova forma de pensar, um projeto de justiça com o escopo na efetivação dos direitos fundamentais da criança e do adolescente, com reflexos na apuração do ato infracional.

Dentro da adoção da doutrina da proteção integral e contrapondo-se ao anterior direito da situação irregular, o procedimento para o "adolescente em conflito com a lei" passou a possuir regras mais claras que garantissem o direito à ampla defesa e ao contraditório. O Estatuto da Criança e do Adolescente prevê um capítulo inteiro denominado "das garantias processuais" que nada mais é o exemplo da atitude da lei menorista, que passou a pregar o garantismo processual penal.

Realizado o ato infracional, inicia-se a ação socioeducativa por meio da representação do Ministério Público, finalizando o procedimento cabe ao Magistrado à medida socioeducativa adequada.

\section{A REVERSIBILIDADE DO DISCURSO PROTETIVO E SEUS PERIGOS}

David Sanchez Rubio (2006, p.23) anota que a condição de reversibilidade do direito é importante aspecto a ser considerado, sobretudo quando se pretende obter (ou não obter) ações institucionais conformes (ou contrárias a) projetos de justiça. O fenômeno de reversibilidade ganha amplitude quando diagnostica o fato de pessoas comuns, bem como profissionais de direito (inclusive alguns setores da crítica), padecem de confiança quase ingênua no que diz respeito ao nível jurídico-positivo dos ordenamentos, esquecendo e ignorando as tramas sociais de dominação e de império que constitui o paradigma normativo.

Assim, notadamente quando se opera o poder punitivo, as violências organizadas dirigidas contra pessoas e coletivos vulneráveis, possuem alta capacidade de mutação do discurso e das práticas (reversibilidade).

É notório que a proteção à criança e ao adolescente tem uma perspectivai filosófica e política típica do discurso de Direitos Humanos, não estando livre do paradoxo da 
reversibilidade do discurso, entendido como "a condição do direito ser interpretado e aplicado em outro sentido, inclusive contraditório entre si” (CARVALHO, 2013, p.210), que seria a “criação de justificativas e mecanismos aparentemente voltados à satisfação dos direitos humanos, mas que, em sua ação concreta, deflagram violação dos próprios direitos humanos" (CARVALHO, 2013, p.223).

O discurso dos Direitos Humanos acaba por demandar o incremento dos interesses e dos valores a serem protegidos pelo Estado, proporcionando giro no sentido histórico dos direitos humanos, acoplado está o efeito perverso de maximização das malhas repressivas- punitivas face a ingênua conclusão de que o direito penal seria instrumento idôneo para tutelar novo bens jurídicos.

Ocorre que este processo não fica limitado apenas ao impulso à criminalização primária (elaboração de tipos penais), cujo efeito será a desregulamentação da matéria codificada (descodificação). Se o Estado deve intervir de forma a proteger futuras ofensas aos bens jurídicos, tal perspectiva não se restringe apenas aos novos valores e à esfera normativa. A intervenção acaba sendo ampla: no aspecto legal deve atingir pela coação psicológica os nãos desviantes (teoria de prevenção geral negativa), inibindo o corpo social da prática delitiva através do temor da pena; e no plano executivo deve atingir o autor do crime, criando condições para atuação do corpo criminológico sobre o desviante, com objetivo de reabilitação (teoria da prevenção especial positiva), de forma que não volte a delinquir.

Este breve relato é importante para entender que o esforço Estatal, com especial reflexo na área da infância, que passa a direcionar o exercício do poder punitivo não somente nos adolescentes que cometeram algum crime, mas aqueles que ainda não estão "civilizados", com o discurso que se visa com isso o "bem dos próprios adolescentes e o fornecimento das condições formais e materiais que possibilitem os membros da comunidade atingir a plena realização pessoal (ideal de felicidade)".

Assim, mesmo sem uma sentença no processo de apuração de ato infracional é possível à aplicação da pena antecipada, "antes de iniciado o procedimento judicial para apuração de ato infracional" (126, do ECA), mediante um mecanismo denominado de remissão que "não implica necessariamente o reconhecimento ou comprovação da responsabilidade" (art.127, do ECA), podendo aplicar "qualquer das medidas previstas em lei, exceto a colocação em regime de semi-liberdade e a internação (art.127, do ECA) ".

Neste quadro, a sanção estatal deve adquirir sentido positivo, promovendo não somente coação aos não desviantes (temor pela autoridade), mas fornecendo supostos meios 
para que o infrator não incorra novamente no delito e seja integrado na e pela sociedade. $\mathrm{O}$ exercício do direito de punir passa a ser norteado pela ideia de prevenção geral positiva, consolidando as teorias elaboradas pela criminologia positivista (paradigma etiológicocausal), claramente adotado pelo Estatuto da Criança e do Adolescente e pelo já referido Sistema Nacional de Atendimento Socioeducativo (Sinase).

O discurso reversivo que pode ter a "doutrina da proteção integral" - que com o pretexto de garantir direitos acaba por violar direitos - tem um "quê" de esquizofrenia, doença que dificulta a distinção entre as experiências reais e imaginárias, interfere no pensamento lógico, nas respostas emocionais normais e comportamento esperado em situações sociais.

No imaginário o discurso visa garantir que o adolescente que se encontre processado pelo Estado tenha mais direitos que um adulto, porém no mundo real, ou nas experiências reais, o que se vê e violação de direitos básicos.

Agostinho Ramalho (1994, p.30-50) questionava-se "Quem nos protege da bondade dos bons?", pois no "ponto de vista do cidadão comum, nada nos garante, 'a priori', que nas mãos do Juiz estamos em boas mãos, mesmo que essas mãos sejam boas. (...) enfim, é necessário, parece-me, que a sociedade, na medida em que o lugar do Juiz é um lugar que aponta para o grande outro, para o simbólico, para o terceiro."

Vivemos na era da expansão punitiva que encontra suas raízes no medo proporcionado pela sociedade do espetáculo, e como dita Bauman (2008, p.173), o medo estimula a ação defensiva, enraizando-se em nossos propósitos e rotina diária. Assim, paradoxalmente, propõe-se o cárcere daqueles causadores de medo (os temidos) a fim de libertar para a vida os que sentem temor (os medrosos?), assim, "Em nome do bem manipulam a insegurança constitutiva do sujeito".

O juiz também é um consumidor do discurso alarmista (do medo e do risco) acerca da ameaça da criminalidade sobre a ótima substancialmente democrática na solução dos inevitáveis conflitos sociais. O combate ao crime e aos criminosos parece - ilusoriamente - encerrar o grande desafio da sociedade contemporânea, cabendo na mão do "homem de bem" ter como principal foco da sua conduta tomar medidas para reprimir a criminalidade.

Pois bem, os adolescentes - mormente os pobres - não sofrem pressão somente por conta do discurso midiático legitimador, que chega as vias até de pleitear perante o Congresso Nacional a redução da imputabilidade penal, mas também da violência estrutural que repercute na violência institucional (ROSA; AMARAL, 2014, p.158), replicando o sistema de 
opressão e injustiça social na apuração de atos infracionais e na aplicação das medidas socioeducativas.

\section{DROGAS E O GRANDE ENCARCERAMENTO}

Segundo a criminóloga venezuelana Rosa Del Olmo (1990) a economia liberal é a força motriz do desenvolvimento do mercado de drogas, legais ou ilegais. Há uma determinação estrutural no caso das drogas, regulada por leis de oferta e de demanda, concomitante a uma carga ideológica e emocional que criou "o mito da droga disseminado pela mídia e acolhido pelo imaginário social, a partir de uma estratégia dos países capitalistas centrais, responsáveis pela volumosa demanda por drogas no mercado internacional.

Nos Estados Unidos, conflitos econômicos foram transformados em conflitos sociais que se expressaram em conflitos sobre determinadas drogas. A primeira lei federal contra a maconha tinha como carga ideológica a sua associação com imigrantes mexicanos que ameaçavam a oferta de mão-de-obra no período da Depressão. O mesmo ocorreu com a migração chinesa na Califórnia, desnecessária após a construção das estradas de ferro, que foi associada ao ópio. No Sul dos Estados Unidos, os trabalhadores negros do algodão foram vinculados a cocaína, criminalidade e estupro, no momento de sua luta por emancipação. O medo do negro drogado coincidiu com o auge dos linchamentos e da segregação social legalizada. Estes três grupos étnicos disputavam o mercado de trabalho nos Estados Unidos, dispostos a trabalhar por menores salários que os brancos.

O problema da droga está situado no nível econômico e ideológico. Com a transnacionalização da econômica e sua nova divisão do trabalho, materializam-se novas formas de controle nacional e internacional. Foi criado todo um sistema jurídico-penal com a finalidade de criminalizar e apenar determinadas drogas. O sistema neoliberal produz uma visão esquizofrênica das drogas, especialmente a cocaína: por um lado estimula a produção, comercialização e circulação da droga, que tem alta rentabilidade no mercado internacional, e por outro lado constrói um arsenal jurídico e ideológico de demonização e criminalização desta mercadoria tão cara à nova ordem econômica.

Alessandro Baratta (1992), relaciona a teoria do poder em Foucault com a atual política anti-drogas. Ele analisa a imagem social estereotipada do criminoso (classes proletárias, minorias raciais e grupos marginalizados) e o fenômeno que faz com que a criminalização 
de deter- minadas substâncias preceda o aparecimento do problema social. A dramática concentração da opinião pública e da ação repressiva do Estado não tem como fator determinante o incremento do consumo real, mas sim o incremento do controle levado a cabo pela medicina e pelo direito penal. São movimentos ligados à disputa de poder interno e internacional. $\mathrm{O}$ autor insere a atual política de drogas no sistema de poder pastoral do Estado tecnocrático, onde a criminalização substitui a delimitação de segmentos sociais.

Vera Regina Pereira Andrade (2013, p.82) sintetiza a hipótese central do livro de Salo de Carvalho, A política criminal de drogas no Brasil: do discurso oficial às razões da descriminalização, nos seguintes termo:

\begin{abstract}
E senso comum a ideia de que o combate à criminalidade e particularmente ao uso e tráfico de entorpecentes são fortemente obstaculizados, no Brasil, pela inexistência de uma adequada política criminal. A hipótese aqui desenvolvida e fundamentada rompe com este senso comum precisamente ao afirmar que tal política 'existe' e tem uma coerência interna. Trata-se de uma política de guerra, combate ou beligerância (genocida) que, inserida num processo de transnacionalizaçäo ou globalização do controle social - gerenciado pelo capitalismo central - é potencializada, no Brasil, por uma tríplice base ideológica: a ideologia da defesa social (a nível dogmático) complementada pela ideologia da segurança nacional (a nível de segurança pública), ambas ideologias em sentido negativo instrumentalizadas (a nível legislativo) pelos movimentos de lei e ordem (como sua ideologia em sentido positivo). (...) $\mathrm{O}$ mote que sustenta toda a argumentação é o da distinção entre o discurso oficial (declarado) e a funcionalidade real da política criminal de drogas (não declarada) pondo a descoberto esta última e situando o primeiro como o seu discurso legitimador, o que remete, diretamente, para o conceito e o funcionamento da ideologia no interior do sistema de controle pena"
\end{abstract}

Salo de Carvalho lança crítica apontando que "aquelas ideologias ocultadas pelos aparelhos de Estado que inviabilizam a otimização dos direitos humanos, demonstrando a dicotomia existente entre o discurso oficial e a funcionabilidade do sistema de drogas fundados em legislações penais do terror".

Historicamente a legislação penal sobre drogas no Brasil possui dispositivos vagos e indeterminados e uso abusivo de normas penais em branco, que "acabaram por legitimar sistemas de total violação das garantias individuais". Ainda de acordo com Salo de Carvalho o alinhamento legal do Brasil à política norte-americana, a partir dos anos setenta, através da absorção do discurso central em que o inimigo interno seria o produtor e o traficante. Para ele o ápice do modelo jurídico político ocorre ao final da década de setenta e início da década de oitenta, com a total incorporação dos postulados da Doutrina de Segurança Nacional na concepção de seguridade pública", dentro das categorias desenvolvidas pelos teóricos da ditadura militar (geopolítica, bipolaridade, guerra total e inimigo interno). 


\section{A SELETIVIDADE DE CONTROLE E COMBATE. DESCONSTRUINDO SENSO COMUNS. OS DADOS APURADOS NA VARA DA INFÂNCIA DE ICOARACI - BELÉM - PA}

Ora, como já dito, a seletividade é estrutural (ZAFFARONI; BATISTA, ET AL.2003, p. 47) e, por conseguinte, não há sistema penal no mundo cuja regra geral não seja a criminalização secundária em razão da vulnerabilidade do candidato, sem prejuízo de que, em alguns, esta característica estrutural atinja graus e modalidades aberrantes.

Como já informamos, a pesquisa da Vera Malaguti Batista (2013, p.35) apontou que as drogas seriam o principal fator de criminalização da juventude, pois $49 \%$ dos adolescentes entraram no sistema de apuração no ato infracional envolvidos com a acusação de tráfico (38\%) e consumo (11\%) de drogas. A maioria desses meninos vêm de morros, favelas e bairros pobres e $38 \%$ são analfabetos.

A pesquisa realizada na Vara da Infância de Icoaraci apontou que as drogas também representariam o principal processo de criminalização, conforme gráfico a seguir:

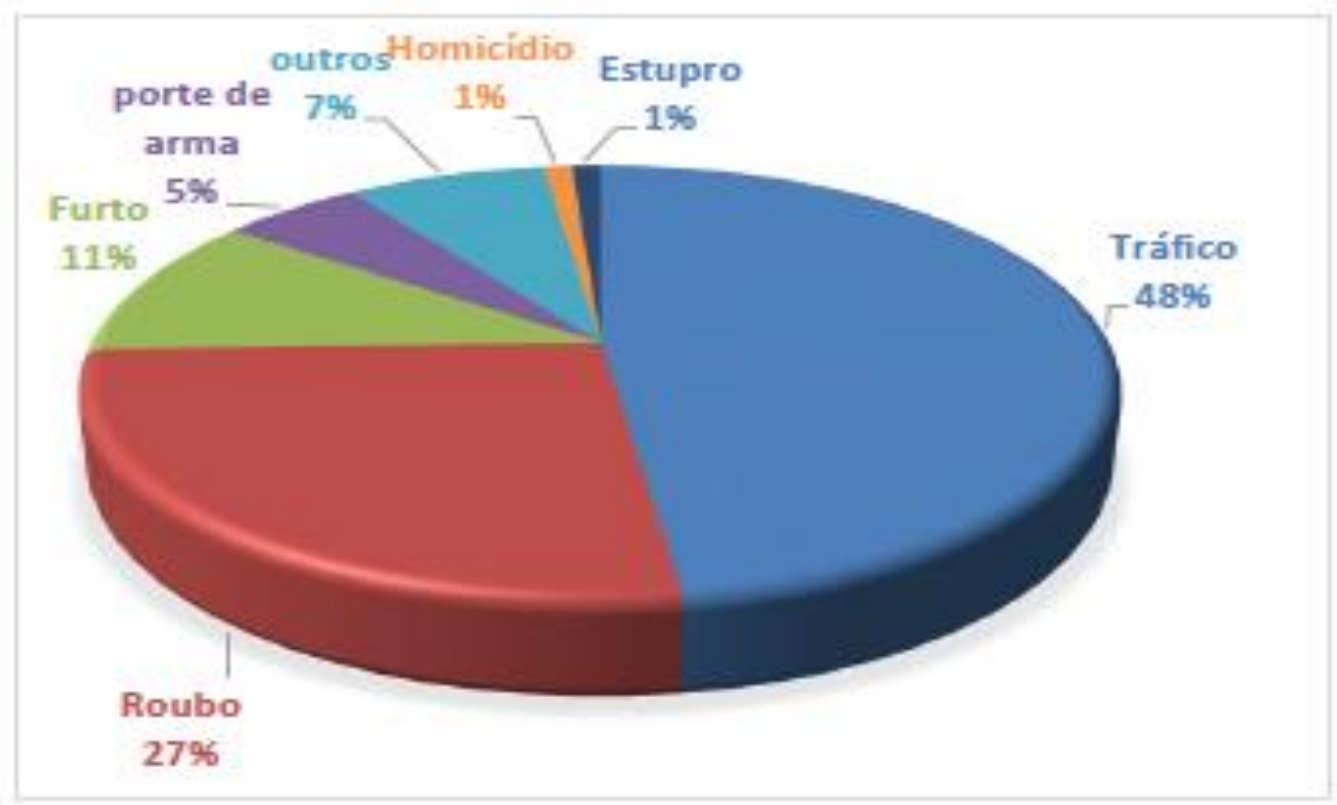


Chama atenção do pesquisador, que o argumento da Proposta de Emenda Constitucional 171/93, que prevê a diminuição da maioridade penal para adolescentes de 16 a 18 anos que cometem crimes hediondos, de que seriam os adolescentes os grandes responsáveis por crimes violentos-hediondos não encontram respaldo numericamente, pois na pesquisa os crimes hediondos arredondando para cima não chegaram a $2 \%$.

A criminalização por faixa etária ocorreu segundo os seguintes dados:

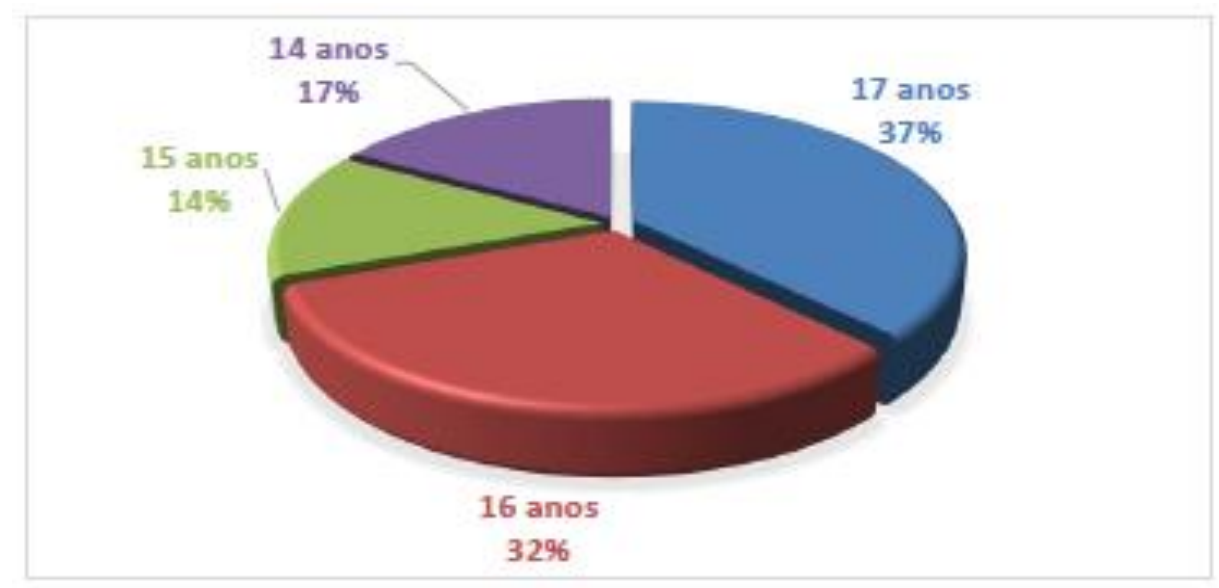

Os adolescentes em sua grande maioria se auto declararam de cor parda:

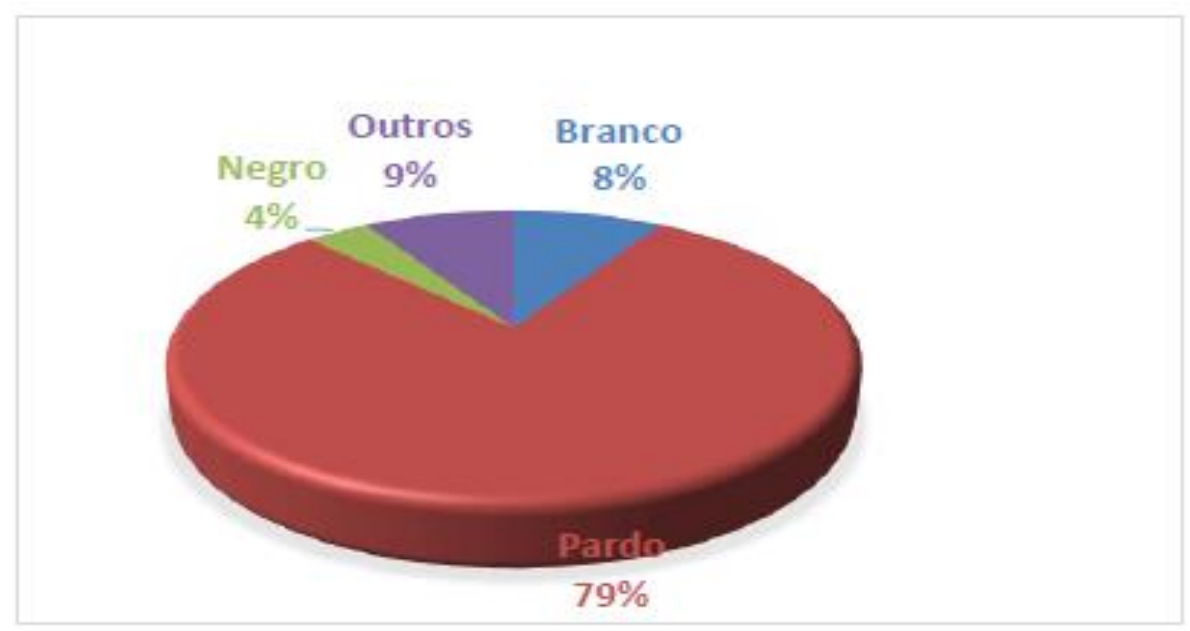


O que mais chamou atenção do pesquisador é o fato do atraso escolar ser forte fator de criminalização dos adolescentes, eis que somente $1 \%$ dos representados estavam na série correta segundo a sua idade, estando os outros $99 \%$ com algum atraso escolar. Ainda quando a este dado, quanto aos adolescentes de 17 (dezessete) anos, que deveriam estar a terceira série do ensino médio, se preparando para realizar o vestibular, a pesquisa demonstrou que 93\% (noventa e três por centos) não possuem o ensino fundamental completo, conforme se demonstra com os seguintes gráficos.

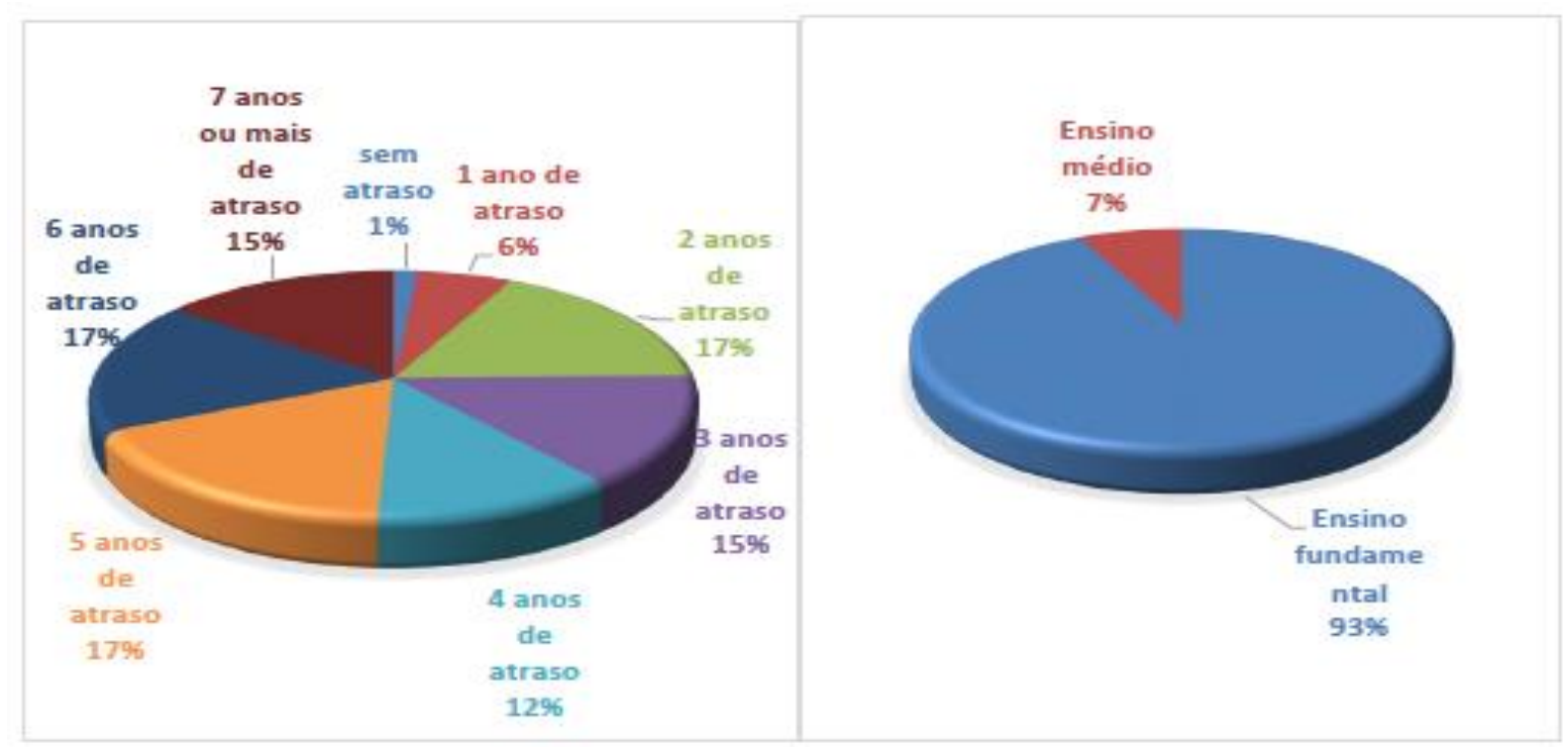

No que tange a situação socioeconômica, apesar de não ser possível extrair dos autos processuais de forma detalhada este dado, é fundamental esclarecer que durante o período de pesquisa que se estendeu dos meses de abril a junho de 2015, nenhum processo envolveu advogado particular, o que demonstra, em especial, que os familiares não tiveram condições de contratar um.

\section{CONCLUSÕES}

A criminalização secundária é a ação punitiva sobre as pessoas que infringem as normas penais, ou seja, o programa penal posto em prática. Criminologia Crítica (BARATTA, 2012, p. 161) mostra o crime como qualidade atribuída ao comportamento ou pessoas pelo sistema de justiça criminal - seu objeto é, portanto, não a criminalidade, mas a criminalização: a criminalidade é um fato socialmente constituído pela distribuição de cargas negativas a fatos e a pessoas, por meio de processos de criminalização. 
$\mathrm{Na}$ perspectiva da criminologia crítica, a criminalidade se revela, principalmente, como um status atribuído a determinados indivíduos, mediante uma dupla seleção: em primeiro lugar, a seleção de bens protegidos penalmente, e dos comportamentos ofensivos destes bens, descritos nos tipos penais; em segundo lugar, a seleção dos indivíduos estigmatizados entre todos os indivíduos que realizam infrações a normas penalmente sancionadas.

A seletividade operacional da criminalização secundária atinge apenas aqueles que têm baixa defesas perante o poder punitivo, aqueles que se tornam mais vulneráveis à criminalização secundária porque: a) suas características pessoais se enquadram no estereótipo criminal; b) sua educação só lhes permite realizar ações ilícitas toscas e, por conseguinte, de fácil detecção; e c) porque a etiqueta suscita a assunção do papel correspondente ao estereótipo, com o qual o seu comportamento acaba correspondendo ao mesmo. Em suma, as agências acabam selecionando aqueles que circulam pelos espaços públicos com o figurino social dos delinquentes, prestando-se à criminalização - mediante as suas obras toscas - como seu inesgotável combustível.

Quase 20 anos se passaram da pesquisa realizada por Vera Malaguti Batista (2013), porém os dados apontam que a criminalização secundária continua recaindo sobre o mesmo grupo de jovens, os adolescentes de família pobre, cor parda, e com grande atraso escolar, em especial para os adolescentes que tem entre 16 (dezesseis) e 17 (dezessete) anos são alvos prioritários do processo de criminalização e do combate ao tráfico de drogas.

Por não haver entre os processos investigados qualquer processo envolvendo o ato infracional equiparado ao crime de uso de substância, chega-se à conclusão que o adolescente que se enquadra nesse estereótipo e for encontrado com substância ilícita terá grandes probabilidades de ser responder representação de ato infracional ao crime equiparado ao tráfico de drogas e não por uso de drogas.

Ressalta-se, a luz da criminologia crítica, não é a pobreza e a educação deficiente etc. as causas do delito, fatores condicionantes dos ilícitos desses segmentos sociais, mas, sobretudo, de sua criminalização, ao lado qual se espalha, impune, todo o oceano de ilícitos dos outros segmentos, que os comete com menor rudeza ou mesmo com refinamento.

Assim como a Vera Malaguti Bastista na obra de referência (2003, p.71) observou que era "impressionante como a maioria esmagadora dos casos se refere a meninos pobres; as elites resolvem seus casos em outras instâncias, informais e não segregadoras”, poderíamos observar a partir dos dados extraídos da pesquisa, em que pese se tratar de locais diferentes e 
quase duas décadas que o segundo levantamento foi feito em relação ao primeiro, a realidade é a mesma e as conclusões se mostram semelhantes.

Portanto, o quadro delineado demonstra que as conclusões de Vera Malaguti Bastista de que seria a justiça juvenil, a parte mais sensível e problemática de todo o sistema punitivo, pois o "caráter seletivo e distributivo alcançam seu ponto mais alto" (2013, p.25), podem ser reafirmadas pelos dados levantados.

\section{REFERÊNCIAS}

ARAUJO. Fernanda Carolina de. Maioridade penal: aspectos criminológicos. IN: Criminologia e os problemas na atualidade. São Paulo: Atlas, 2008.

BARATTA, Alessandro. Criminologia crítica e crítica do direito penal: introdução à sociologia penal. 6. ed. Rio de Janeiro: Revan, 2012.

Fundamentos ideológicos da atual política criminal sobre drogas. Só socialmente. Rio de Janeiro, Relume-Dumará, 1992.

BATISTA, Vera Malaguti. Introdução crítica à criminologia brasileira. 2. ed. Rio de Janeiro: Revn, 2012.

BAUMAN, Zygmunt. Medo líquido. Rio de Janeiro: Zahar, 2008.

CAMARA FEDERAL. Notícias. 2015. Disponível em: <http://www2.camara.leg.br/camaranoticias/noticias/POLITICA/491507-CAMARAAPROVA-EM-1-TURNO-REDUCAO-DA-MAIORIDADE-PENAL-EM-CRIMESHEDIONDOS.html, > Acesso em: 8 mar. 2016.

CARVALHO, Salo de. Antimanual da política criminal. 5. ed. São Paulo: Saraiva, 2013.

A Política criminal de drogas no Brasil: do discurso oficial às razões da descriminalização. 2. ed. Rio de Janeiro: LUAM, 1997.

ISHIDA, Valter Kenji. Estatuto da criança e do adolescente: doutrina e jurisprudência.15.ed.-São Paulo: Atlas. 2014, p.246.

MARQUES NETO, Agostinho Ramalho. O Poder Judiciário na Perspectiva da Sociedade Democrática: O Juiz Cidadão. In: Revista ANAMATRA. São Paulo, n. 21, p. 30-50, 1994

MIGLIARI, Maria de Fátima. Infância e adolescência pobres no Brasil. Rio de Janeiro:PUC, 1993.

OMO, Rosa Del. A face Oculta da droga. Rio de Janeiro, Revan, 1990. 
ROSA, Alexandre Morais da; AMARAL, Augusto Jobim do. Cultura da punição: A ostentação do horror. Rio de Janeiro: Lumen Juris, 2014.

SANCHEZ, Rubio. Reversibilidade do Direito: os Direitos Humanos na Tensão entre o mercado, os Seres Humanos e a Natureza. Revista de Estudos Criminais (22). Porto Alegre: Notadez/PPGD-Crim PUCRS/ITEC, 2006, p.23.

ZAFFARON, Eugênio Raul et al. Direito penal brasileiro: teoria geral do direito penal. 4 . ed. 1. reimp. Rio de Janeiro: Revan, 2003, maio/jul. 2011-2013. v.1.

ZAFFARONI, Eugênio Raul. "verbete do Advogado", in Estatuto da Criança e do Adolescente Comentado. São Paulo, Malheiros, 1992. 